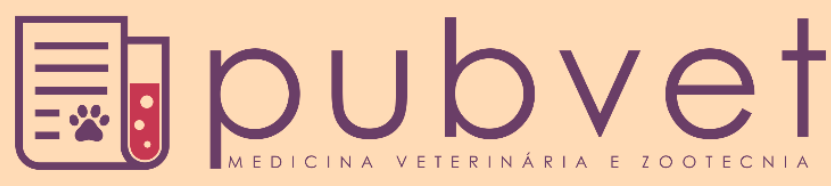

https://doi.org/10.31533/pubvet.v15n10a945.1-5

\title{
Raiva em cães e gatos no Brasil: Análise descritiva
}

\author{
Beatriz Cavalcanti da Silva ${ }^{1}$, Carolina Souza dos Santos ${ }^{1}$, Diego Souza do Amor Divino ${ }^{1}$, Juliana \\ Bonetti Donon ${ }^{1}$, Maria Estefany de Amorim Ferreira ${ }^{1}$, Nívea Barbosa Gonçalves ${ }^{1}$, Paula \\ Rodrigues Cobo ${ }^{*}$, Thaís Aparecida da Silva Oliveira ${ }^{1}$, Thiago Menezes dos Reis ${ }^{1}$, Vitor Pereira \\ dos Santos Souza ${ }^{1}$, Willian Américo Mendes ${ }^{1}$
}

${ }^{I}$ Aluno(a) de graduação, Universidade Nove de Julho, Cidade, Brasil

*Autor para correspondência, E-mail: paula.cobo@live.com

\begin{abstract}
Resumo. A fácil transmissão do vírus da raiva entre cães e gatos domésticos e em animais de situação de rua, na qual ocasiona a disseminação patogênica até para humanos, é um grande problema de saúde pública no Brasil. A epidemiologia brasileira realizada pela profilaxia de campanhas de vacinação contra raiva, tem possibilitado a mudança significativa dos quadros de animais infectados notificados ao Ministério da Saúde e Ministério da Agricultura Pecuária e Abastecimento. Ainda que notificados, os quadros necessitam ser investigados e potencialmente correlacionados com os quadros de humanos também infectados e falhas no abastecimento de vacinações anuais. Nessa análise descritiva, observou-se que prioritariamente a região Nordeste liderou com maior número de casos pelo vírus da raiva nos 3 anos analisados (2017, 2018 e 2019). Dessa maneira, observa-se que mesmo com abrangências nacionais positivas, ainda se obtiveram casos confirmados, exceto uma ideal regulação e manutenção de casos em que não se obtiveram casos confirmados. Conclui-se que, doenças zoonóticas demonstram gradativamente a diminuição á medida que sua profilaxia mantém seu linear.
\end{abstract}

Palavra-chave: Zoonoses raiva canina, raiva felina, epidemiologia, saúde pública

\section{Rabies in dogs and cats in brazil: Descriptive analysis}

\begin{abstract}
The easy transmission of rabies virus among domestic and street dogs and cats, in which it causes pathogenic dissemination even to humans is a major public health problem in Brazil. The Brazilian epidemiology carried out through the prophylaxis of rabies vaccination campaigns has enabled the significant change in the pictures of infected animals notified to the Ministries of Health, Livestock Agriculture and Supply. Although notified, the pictures need to be investigated and potentially correlated with the human pictures also infected and failures of annual vaccination supplies. In this descriptive analysis, it was observed that as a priority the Northeast region led with the highest number of cases of rabies virus in the 3 years analyzed (2017-2018-2019). Thus, it is observed that even with positive national coverage, confirmed cases were still obtained, except for an ideal regulation and maintenance of cases where no confirmed cases were obtained. It is concluded that zoonotic diseases are gradually decreasing as their prophylaxis maintains its linear.
\end{abstract}

Keyword: Zoonoses, canine rage, feline rage, epidemiology public health

\section{Introdução}

A raiva é uma zoonose de fácil transmissão virótica que ocorre pela penetração do vírus Lyssavirus, pertencente à família Rhabdoviridae, por meio de mordeduras, arranhaduras e lambeduras (Costa, 2000; Morato et al., 2011; Novais \& Zappa, 2008). 
Cães e gatos infectados livres nas ruas transmitem entre si o vírus da raiva, podendo comprometer a conservação de animais silvestres pela combinação de poluição patogênica, ou seja, a disseminação de patógenos para hospedeiros ingênuos (Morato et al., 2011; Smith et al., 2019).

A imunização de cães domésticos com vacinas veterinárias tradicionais pela rota parenteral levou à extinção virtual da raiva transmitida por caninos em países desenvolvidos como no Brasil (Rupprecht et al., 2004). Desse modo, a vacinação de animais domésticos tem mudado a epidemiologia da transmissão, determinando uma maior participação de animais silvestres nos casos notificados (Day et al., 2016).

Apesar dos avanços observados e da ausência de efeitos ambientais ou de saúde adversos substantivos, a vacinação oral não é uma panaceia, e deve ser vista como um importante adjunto às técnicas tradicionais de prevenção e controle da medicina humana e veterinária (Rupprecht et al., 2004).

Quando a disposição política, a infraestrutura biomédica e a estabilidade econômica permitem o uso sustentado de medidas de controle (por exemplo, remoção de animais de rua e vacinação parenteral obrigatória), a raiva canina foi significativamente suprimida e até eliminada em grandes áreas geográficas (Rupprecht et al., 2004).

A ocorrência de infecção por raiva em animais não vacinados foi identificada pela detecção de antígenos RABV (vírus da raiva) em tecidos cerebrais de animais mortos ou anticorpos antirrábicos em animais vivos (Wada et al., 2011).

Os indicadores de saúde-doença para a raiva são estritamente relacionados à vacinação, saúde animal e responsabilidade de seus tutores. A responsabilidade do tutor perante seu animal é de extrema relevância para a saúde pública no local onde ele reside, isso implica o cuidado em entender as doenças em que acometem seus animais (Cardoso et al., 2016). Esses indicadores são de importância determinante para à saúde pública no Brasil, uma vez que se trata de uma patologia de notificação compulsória de caninos e felinos, ajudando desta forma na criação de vigilância em saúde e sanitarismo. O risco à saúde pública devido a convivência com estes animais, é ainda maior quando os proprietários desconhecem o modo de transmissão dessas doenças, bem como suas formas de prevenção (Silva, 2003).

Esse artigo abordou os indicativos de prevalência do vírus da raiva de notificados do Ministério da Saúde em todo o território nacional, entre os anos de 2017 à 2019 de cães e gatos de variadas raças e idades, infectados.

\section{Material e métodos}

Trata-se de uma análise qualitativa descritiva de literaturas acadêmicas publicadas e protocolos do Ministérios da Saúde e da Agricultura e Pecuária sobre casos notificados de infectados com o vírus da raiva entre caninos e felinos em todo o Brasil. Separados por regiões brasileiras, os dados são públicos e não existe a necessidade prévia de aprovação do comitê de ética.

Foram selecionadas 18 literaturas para a composição, extraídas do Google Acadêmico, SciElo (Scientific Electronic Library Online), Ministério da Saúde, Secretaria de Vigilância em Saúde - SVS Departamento de Vigilância de Doenças Transmissíveis - DEVIT Coordenação Geral de Doenças Transmissíveis - CGDT; com um corte transversal na abordagem das literaturas de 2017, 2018 e 2019. Foram utilizadas na busca, combinações entre os descritores: Raiva em caninos e felinos, Saúde Pública, Zoonose.

\section{Resultados}

\section{7}

Foram identificados no ano de 2017 que o número de caninos infectados na região Centro-Oeste foram: 1 caso no Estado do Mato Grosso do Sul; Na Região Nordeste obteve 10 casos notificados, sendo: 2 casos no Estado da Bahia; 2 no Ceará; 3 no Maranhão; 1 em Pernambuco; 1 na Paraíba e 1 no Estado de Sergipe. Nota-se que na Região Nordeste no mesmo ano, foram registrados 3 casos de felinos infectados, sendo eles: 1 na Bahia; 1 caso na região de Pernambuco e 1 caso registrado no Estado de Sergipe.

2018

Consta-se que na Região Nordeste obteve 4 casos de notificação de caninos no ano de 2018, sendo eles nos Estados: 2 Ceará; 1 Maranhão; 1 caso registrado no Estado do Rio Grande do Norte; a Região 
Norte obteve 1 caso total de registrados: 1 no Pará; Já na região Sudeste, foram notificados 2 casos de infectados pela raiva, sendo 02 casos na região de São Paulo.

Os números de casos de felinos infectados pela raiva nas regiões brasileiras no mesmo ano, foram de 02 casos, sendo eles no Estado de São Paulo. A Região Nordeste e Sudeste que obtiveram juntas 4 casos notificados: 2 casos registrados no Ceará, 1 caso na Região do Rio Grande do Norte e 1 em São Paulo.

2019

Foram identificadas notificações de caninos em 2019, na região Nordeste, Ceará 2 casos; Rio Grande do Norte 1 caso; Região Sudeste obtendo 1 caso em São Paulo, totalizando 4 casos. Constata-se que o número de casos de Felinos no ano de 2019 na região Sul foram de 2 casos notificados. Sendo eles, 1 registro no Paraná e 1 em Santa Catarina. A Região Sudeste obteve 1 caso notificado, sendo ele: 1 caso na região de Minas Gerais.

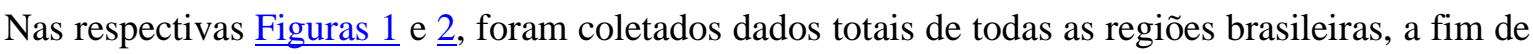
melhor identificar a região em que mais obteve casos notificados pelo vírus da raiva.

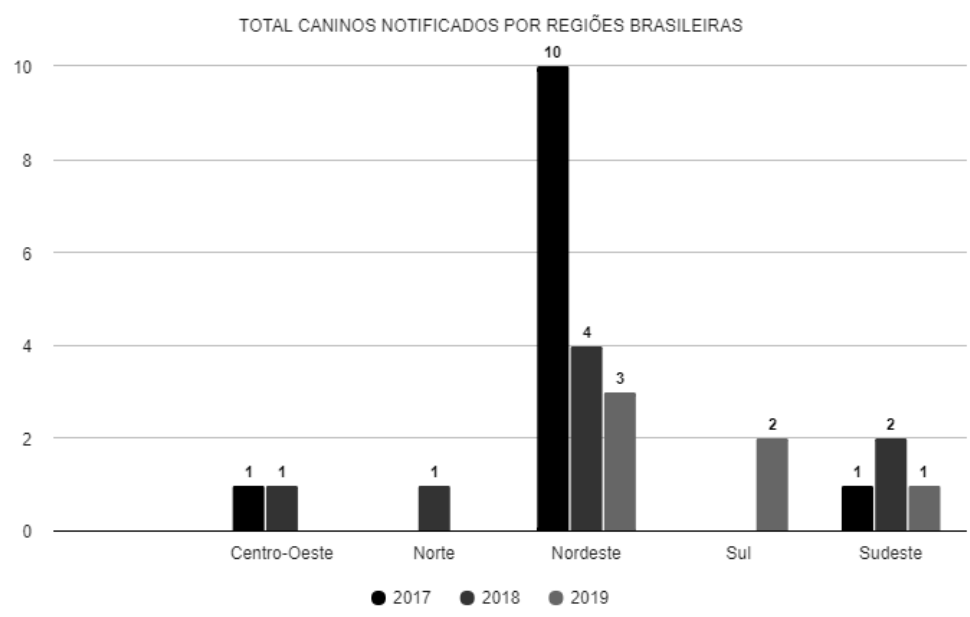

Figura 1. Total de caninos notificados por regiões brasileiras - 2017 a 2019

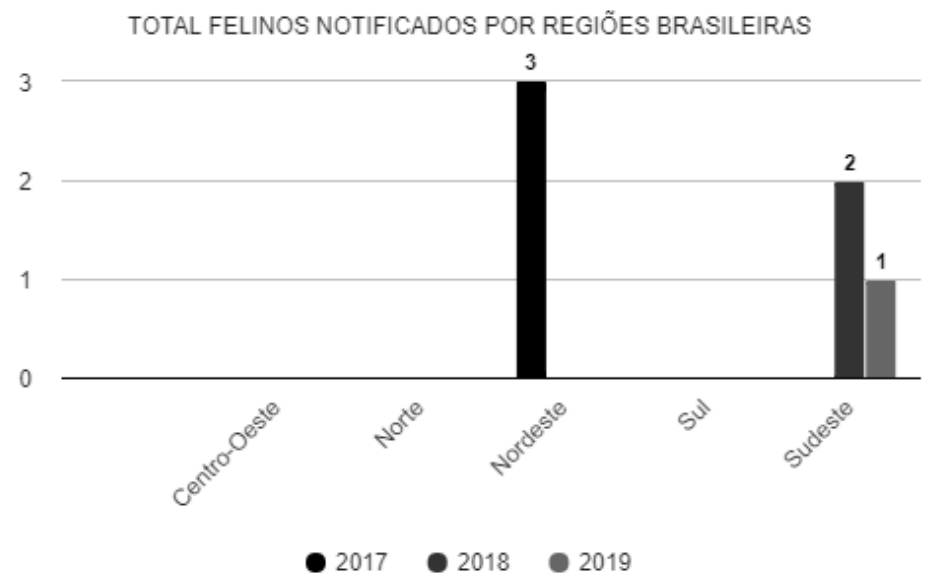

Figura 2. Total de felinos notificados por regiões brasileiras - 2017 a 2019

\section{Discussão}

\section{7}

Observa-se que no ano de 2017, foram 15 casos totais de caninos bem como felinos infectados e notificados pelo vírus da raiva. Sabe-se que no mesmo ano o (Ministério da Saúde, 2020) obteve baixa adoção vacinal, devido ao atraso de chegada laboratorial de vacinas. Demonstrando assim, que mesmo essa abrangência pequena de cobertura vacinal, obtivemos uma resposta à janela imunológica eficaz 
daqueles que foram vacinados em anos anteriores e da mesma região ou adjacente. Nota-se uma prevalência de poucos recursos publicados sobre os casos até o atual momento, uma vez que não estão claros o suficiente para esclarecimentos reais, compondo apenas aqueles casos sintomáticos em humanos que recorreram ao atendimento médico, de qualquer natureza patológica conforme protocolo do SUS (Sistema Único de Saúde). Desta maneira a incidência avaliada nos achados notificados pelo Ministério ainda são vagos e persistem, em uma análise feita nas publicações de Vargas et al. (2019).

2018

Essa amostra analisada, pode-se observar uma média acentuação de casos na região sudeste comparado ao ano anterior. No mesmo período, os índices de casos entre caninos e felinos ainda estava diminuído e controlado, nesta mesma época foram observadas na literatura, segundo Ministério da Saúde 2020, um surto da raiva em morcegos hematófagos

2019

Em 2019 foram registrados um total de 7 casos, comparados aos notificados pelo Ministério da Saúde (2020), do mesmo ano que correlata 07 casos notificados. No mesmo ano de 23 casos totais para raiva canina e felina, cuja variante está sendo investigada. Demonstrando uma diferença de abrangência dos casos cujo existe necessidade de investigação.

A campanha vacinal nas regiões do Ceará, Rio Grande do Norte, demonstra-se que mesmo espécies onde sua abrangência esta coberta, obtiveram casos de infectados pelo vírus da raiva. Comparado também com regiões segundo o (Ministério da Saúde 2020), obtivemos regiões com cobertura vacinal de $100 \%$, porém sem notificações, como, Maranhão, Piauí, Mato grosso do Sul, Mato Grosso, Rondônia e Acre.

\section{Conclusão}

O território Nordestino liderou com o número de casos de infectados pelo vírus da raiva no Brasil, dos 3 anos estudados 2017, 2018 como também o de 2019, tal região apresentou pelo menos um caso, isso se evidencia pela negligência dessa região para com a adoção de métodos de profilaxia contra a raiva entre cães e gatos, o que culminou para o seu agravamento. Desse modo, deve-se salientar que, por mais que atualmente existem tecnologias que são utilizadas para combate a disseminação de raiva no Brasil, tendo como exemplar a vacina, lamentavelmente, não vem sendo utilizada com maestria. Sendo assim, cabe a uma melhor organização que aumente a prevenção contra essa zoonose nas principais localidades que apresentaram a manifestação dessa doença, assim corroborando para a sua estabilização e controle.

\section{Referências bibliográficas}

BRASIL. Ministério da Agricultura, Pecuária e Abastecimento. Secretaria de Defesa Agropecuária. Controle de raiva dos herbívoros. Brasília, 2005.

BRASIL. Ministério da Saúde. Raiva: O que é, causas, sintomas, tratamento, diagnósticos e prevenção. Disponível em: <> Acesso em: 09, junho de 2020.

BRASIL. Ministério da Saúde. Secretaria de Vigilância em Saúde. Departamento de Vigilância Epidemiológica. Normas técnicas de profilaxia da raiva humana/Ministério da Saúde, Secretaria de Vigilância em Saúde, Departamento de Vigilância Epidemiológica. Brasília: Ministério da Saúde,2011.

BRASIL. Ministério da Saúde. Secretaria de Vigilância em Saúde. Departamento de Vigilância das Doenças Transmissíveis. Manual de vigilância, prevenção e controle de zoonoses: normas técnicas e operacionais [recuso eletrônico] / Ministério da Saúde, Secretaria de Vigilância em Saúde, Departamento de Vigilância das Doenças Transmissíveis - Brasília: Ministério da Saúde, 2016.

BRASIL. Ministério da Saúde. Secretaria de Vigilância em Saúde. Departamento de Vigilância Epidemiológica. Protocolo de Tratamento da raiva humana no Brasil/ Ministério da Saúde, Secretaria de Vigilância em Saúde, Departamento de Vigilância Epidemiológica - Brasília: Ministério da Saúde, 2011.

Cardoso, D. P., Oliveira, R. P., Estrela, D. S., Saraiva, L. A., Farias, M. P. O., \& Silva, P. O. (2016). Perfil dos tutores de cão e gato no município de Bom Jesus-PI. PUBVET, 10(8), 580-635. https://doi.org/10.22256/pubvet.v10n8.580-586. 
Costa, W. A. (2000). Manual de profilaxia da raiva humana. Instituto Pasteur.

Day, M. J., Horzinek, M. C., Schultz, R. D., \& Squires, R. A. (2016). Diretrizes para a vacinação de cães e gatos. Journal of Small Animal Practice, 57, 699-706.

Ministério da Saúde. Secretaria de Vigilância em Saúde. Guia de Vigilância em Saúde. Brasília, 2014.

Ministério da Saúde. Secretaria-Executiva Departamento de Monitoramento e Avaliação do SUS. Manual da oficina de capacitação em monitoramento e avaliação em saúde. Brasília, 2013.

Mistério da Saúde. Secretaria de Vigilância em Saúde. Departamento de Vigilância Epidemiológica. Guia de vigilância epidemiológica. 7. ed. Brasília, 2009.

Ministério da Saúde. Portaria ${ }^{\circ} 1.271$, de 6 de junho de 2014. Define a Lista Nacional de Notificação Compulsória de doenças, agravos e eventos de saúde nos serviços de saúde públicos e privados em todo o território nacional, nos termos do anexo, e dá outras providências. Disponível em <http://bvsms.saude.gov.br/bvs/saudelegis/gm/2014/prt11271_06_0

Ministério da Saúde. Secretaria de Vigilância em Saúde. Departamento de Vigilância Epidemiológica. Doenças infecciosas e parasitárias: guia de bolso. 8. ed. Brasília, 2008.6_2014.html>. Acesso em: 20 abril 2020.

Morato, F., Ikuta, C. Y., \& Ito, F. H. (2011). Raiva: uma doença antiga, mas ainda atual. Revista de Educação Continuada Em Medicina Veterinária e Zootecnia Do CRMV-SP, 9(3), 20-29.

Novais, B. A. F., \& Zappa, V. (2008). Raiva em bovinos-revisão de literatura. Revista Científica Eletrônica de Medicina Veterinária Da Faculdade de Medicina Veterinária e Zootecnia de Garça, 10.

Rupprecht, E. C., Hanlon, C., \& Ardósia, D. (2004). Vacinação oral da vida selvagem contra a raiva: oportunidades e desafios na prevenção e controle. Developmet of Biologia, 119, 173-184.

Silva, E. N. (2003). Doenças de transmissão vertical. In M. Macari \& E. Gonzales (Eds.), Manejo da Incubação. FACTA.

Smith, L. M., Hartmann, S., Munteanu, A. M., Dalla Villa, P., Quinnell, R. ., \& Collins, L. M. (2019). A eficácia do manejo populacional de cães: Uma revisão sistemática. Animais, 9, 1020.

Vargas, A., Romano, A. P. M., \& Merchán-Hamann, E. (2019). Human rabies in Brazil: a descriptive study, 2000-2017. Epidemiologia e Serviços de Saúde, 28, e2018275.

Wada, M. Y., Rocha, S. M., \& Maia-Elkhoury, A. N. S. (2011). Situação da raiva no Brasil, 2000 a 2009. Epidemiologia e Serviços de Saúde, 20(4), 509-518.

Histórico do artigo:

Recebido: 3 de junho de 2021

Aprovado: 9 de julho de 2021
Licenciamento: Este artigo é publicado na modalidade Acesso Aberto sob a licença Creative Commons Atribuição 4.0 (CC-BY 4.0), a qual permite uso irrestrito, distribuição, reprodução em qualquer meio, desde que o autor e a fonte sejam devidamente creditados. 